\title{
The Relationship Between Obesity, Insulin Resistance, and Conjunctival Impression Cytology
}

\author{
Murat DAĞDEVIREN¹ (D), Mustafa ALTAY ${ }^{1}$ (D), Zennure YILDIZ² ${ }^{\mathbb{D}}$, Gülçin ŞiMŞEK ${ }^{3}$ (D), Mehmet ÇITIRIK ${ }^{4}$ (D), \\ İhsan ATEŞ ${ }^{5}$ (D), Tanyel Sema DAĞDEViREN ${ }^{6}$ (D), Canan YILDIZ ${ }^{7}$ D, Tuğba ŞAHIN ${ }^{2}$
}

Department of ${ }^{1}$ Endocrinology and Metabolism, ${ }^{2}$ Ophthalmology, and ${ }^{3}$ Pathology, University of Health Science, Keçiören Health Administration and Research Center, ANKARA, TURKEY, ${ }^{4}$ Department of Ophthalmology, University of Health Science, Ulucanlar Health Administration and Research Center, ANKARA, TURKEY ${ }^{5}$ Department of Internal Medicine, University of Health Science, Ankara Numune Health Administration and Research Center, ANKARA, TURKEY

Department of ${ }^{6}$ Family Practice, ${ }^{7}$ Internal Medicine, University of Health Science, Keçiören Health Administration and Research Center, ANKARA, TURKEY

\begin{abstract}
Objective: This study was designed to determine whether obesity causes the development of metaplasia in conjunctival epithelial cells.

Material and Method: A total of 61 volunteer participants who had no previous history of illness or drug use were involved in this study. Of those, 20 were obese, and 41 were of normal weight. We measured the glucose and insulin values of all volunteers. We also measured the Body Mass Index (BMI) and Homeostasis Model Assessment for Insulin Resistance (HOMA IR). The impression cytology method was used to analyze the conjunctival epithelium cells, and to classify them between Grades 0 to 3 according to the Nelson criteria.

Results: There was a certain level of loss of goblet cells on the $90 \%$ level as well as squamous metaplasia (Grade $2-3$ ) in $80 \%$ of the obese participants and impression cytology was found to be normal in only two patients. The expected results were observed in $56.1 \%$ of the control group where the squamous metaplasia rate was nearly $17 \%(\mathrm{p}<0.001) .90 .9 \%$ of the grade 3 patients were obese. The variables as independent predictors were found to indicate the existence of abnormal cytology in the conjunctiva at various levels; BMI (OR: $1.24 ; \mathrm{p}=0.002)$ and HOMA IR $(\mathrm{OR}=28.6 ; \mathrm{p}=0.001)$ in a Model I multivariable regression model, and the existence of obesity $(\mathrm{OR}: 11.91 ; \mathrm{p}=0.002)$ and HOMA IR $(\mathrm{OR}=$ $15.08 ; \mathrm{p}<0.001)$ in a Model II multivariable regression model.
\end{abstract}

Conclusion: Obesity was found to be a disorder that causes metaplasia in the conjunctival epithelium cells for the first time.

Key Words: Conjunctiva, Impression cytology, Inflammation, Obesity

\section{INTRODUCTION}

Obesity is a chronic disease that has rapidly increased in terms of frequency, especially over the past three decades, to the point that it is on the verge of becoming a global health pandemic. According to global projections, it is estimated that there are nearly 500 million obese adults worldwide $(1,2)$. The gradual increase in the obesity incidence has also caused the escalation of some diseases such as type 2 diabetes mellitus (DM), hepatosteatosis, various cardiovascular diseases in addition to respiratory tract, neurodegenerative, and biliary disorders, as well as gonadal abnormalities, and certain forms of cancer (3). Furthermore, the systemic inflammation and immune system activation observed in obesity impacts certain organs as well (4-7), one of which is the eye. Obesity and secondary insulin resistance, as well as the related prediabetes and diabetes, may cause retinal dysfunction (8).

(Turk Patoloji Derg 2019, 35:119-127)

Received : 29.11.2018 Accepted : 16.01.2019
Furthermore, obesity may bring about complications such as cataract, macular degeneration, increased intraocular pressure, and dry eye due to Meibomian gland dysfunction (9-11). Additionally, it has been associated with the increasing retinal nerve fiber thickness found in BMI, as well as with central macular thickness and choroidal thickness (12). Research indicates that obesity may have certain effects on certain parts of the eye with different mechanisms. When it comes to inflammation, it would be expected that conjunctival cells may also be affected as well due to such diseases. Nevertheless, there is no clear evidence or data that shows how obesity affects either the conjunctival surface or epithelium cells.

The principle objective of this study was to evaluate the ocular surface cells in obese patients using impression cytology, as well as to determine whether obesity had caused metaplasia in these cells.
Correspondence: Murat DAĞDEVİREN

Keçiören Training and Research Hospital,

Department of Endocrinology and Metabolism, ANKARA, TURKEY

E-mail: muratdagdeviren61@hotmail.com Phone: +903123569000 


\section{MATERIALS and METHODS}

Approval was first requested from the hospital's ethics committee (decision dated and numbered: 14.05.2014581) before initiating the study. The work was conducted according to the principles of the Helsinki Declaration, and a written consent concerning the study was obtained from each of the participants.

A total of 61 volunteer participants were involved in this study. Those who were under the age of 18 years, who had active or chronic eye disease, who had an ongoing or systemic disease outside of obesity, who had used systemic drugs, local eye medicine, and/or contact lenses, and/or who had previously undergone any form of eye surgery were excluded from this study. Similarly, those who had used topical cyclosporine, or who had used local or systemic non-steroid anti-inflammatory medicine or steroids over the last 6 months, alongside those who had used any topical treatments for their eyes, and had a history of herpes keratitis, blepharitis, ocular trauma, and/or non-eye surgery were also not included in this study. Furthermore, patients with the punctate epithelial erosion in the cornea were disqualified from the study. Those who did qualify as participants had neither Steven-Johnson syndrome, nor any history of thermal, chemical, or radiation damage. None of the subjects were consumers of tobacco products, alcohol, diuretics, antihistamines, vitamins, antidepressants, or anticholinergic drugs.

The glucose and insulin levels were measured from the peripheral venous blood, between 08:00 to 09:00 in the morning following a 10 hour-minimum fasting period. The Body Mass Index (BMI) was calculated as the body weight $(\mathrm{kg})$ divided by the square of the height $\left(\mathrm{m}^{2}\right)$. Those whose BMI was over $30 \mathrm{~kg} / \mathrm{m}^{2}$ were accepted as obese. The Homeostasis model assessment for insulin resistance (HOMA IR) was calculated using the formula (insulin $\mathrm{x}$ glucose) / 405.

Schirmer's test was applied to both the patients and control groups immediately following a routine eye examination. A standard kit consisting of a $5 \times 30 \mathrm{~mm}^{2}$ filter paper was placed under the temporal part of the lower eyelid. Participants with values of less than $5 \mathrm{~mm}$ in the measurements after a 5 -minute period were assumed to be abnormal, and were also disqualified. The stability of the tear-film layer was evaluated by determining the tear break-up time (TBUT) test. For the TBUT, a fluorescein-impregnated strip was placed in the patient's lower conjunctival sac after being wetted with a non-preserved saline solution. The patient was asked to blink three to five times, and then to keep their eyes open. The time between the last blink and the appearance of the first dark dot was recorded as the TBUT. The mean of three measurements was recorded. A value of $<10 \mathrm{~s}$ was accepted as abnormal.

The impression cytology technique was used to evaluate the conjunctival ocular surface. This technique was conducted after topical anesthesia was applied to the conjunctiva. The $4 \times 5 \mathrm{~mm}$ cellulose acetate filter papers (MFS, Advantec MFS, Pleasanton, USA, pore size $0.2 \mu \mathrm{m}$ ) were placed under the superior temporal interpalpebral conjunctiva $5 \mathrm{~mm}$ away from the limbus. They were lightly pressed for 5 seconds and pulled away. The samples were fixed with the appropriate solutions, and tinted with dye using Papanicolau's modified version of Gill's technique. The prepared samples were evaluated under a light microscope with a pathologist. The Nelson grade system was used in the classification of the results. Nelson grades conjunctival impression cytology specimens (grades 0-3) based on the appearance of the epithelial cells and the numbers of goblet cells (13).

\section{The Nelson Classification (Figure 1A-D)}

Grade 0: The epithelium cells are small, oval, or rather round, and firmly bonded to one another. Their cytoplasms are eosinophilic colored. The nuclei are large and basophilic. The nucleus-to-cytoplasm rate is $1 / 2$. The goblet cells are relatively prevalent or abundant, bulbous, and densely colored PAS (+).

Grade 1: The cytoplasm-portion of the epithelium cells is eosinophilic-colored, slightly large, and polygonal. They are about to separate from each other. The nuclei are rather small, and the nucleus-to-cytoplasm rate is $1 / 3$. The goblet cells colored with PAS (+) are less prevalent but they are quite similar in terms of both size and shape (early loss of goblet cells).

Grade 2: The coloring of the cytoplasm varies. The epithelium cells are rather large and polygonal. They are sometimes multiple in number, and their nuclei are small. The nucleus-to-cytoplasm ratio is between $1 / 4$ and $1 / 5$. The prevalence of goblet cells is clearly reduced (marked decrease of goblet cells), the volume is small, cell boundaries are barely identifiable, and the PAS (+) coloring is diminished.

Grade 3: The cytoplasm portion of the epithelium cells are eosinophilic-colored, rather large, and polygonal in shape. The nucleus is lost in most of the cells. Those cells containing nucleolus are small, and have an apyknotic structure. The nucleus-to-cytoplasm ratio is $1 / 6$, and cells that are keratinized in appearance are present. The prevalence of goblet cells is low to non-existent (total loss of goblet cells, large epithelial cells). 
All specimens that were grade 1, 2 or 3 were abnormal (loss of goblet cells $=$ abnormal cytology). In essence, grade 2 and 3 inflammations have been dubbed as squamous metaplasia due to their changing of the non-keratinized secretory epithelia into the keratinized non-secretory phase.

\section{Statistical Analysis}

The Statistical Package for Social Sciences (SPSS) for Windows 20 (IBM SPSS Inc., Chicago, USA), alongside the Med Calc 11.4.2 (MedCalc Software, Mariakerke, Belgium) software programs were used for statistical analysis. The normal distribution of the data was evaluated with using the Shapiro-Wilk test. Values with normal distribution were presented as a mean \pm standard deviation. Categorical variables were presented in terms of numbers and percentages. Numerical values in two groups were compared using the Student $\mathrm{T}$ test. The Chi-square and Fisher's exact Chi-square tests were used to compare the categorical data. Numerical values in the grade groups were compared using the ANOVA test. Invariable analysis was utilized in order to determine the effects of potential prognostic factors on a loss of goblet cells. Significant factors were included in the stepwise multivariate logistic regression model, and independent predictors were identified. The diagnostic discrimination of independent predictors in the loss of goblet cells were examined using ROC Curve analysis, or the area beneath the curve. In the statistical analysis, the $\mathrm{p}<0.05$ significance level with a $95 \%$ confidence interval alongside a 5\% margin of error was considered to be statistically significant.
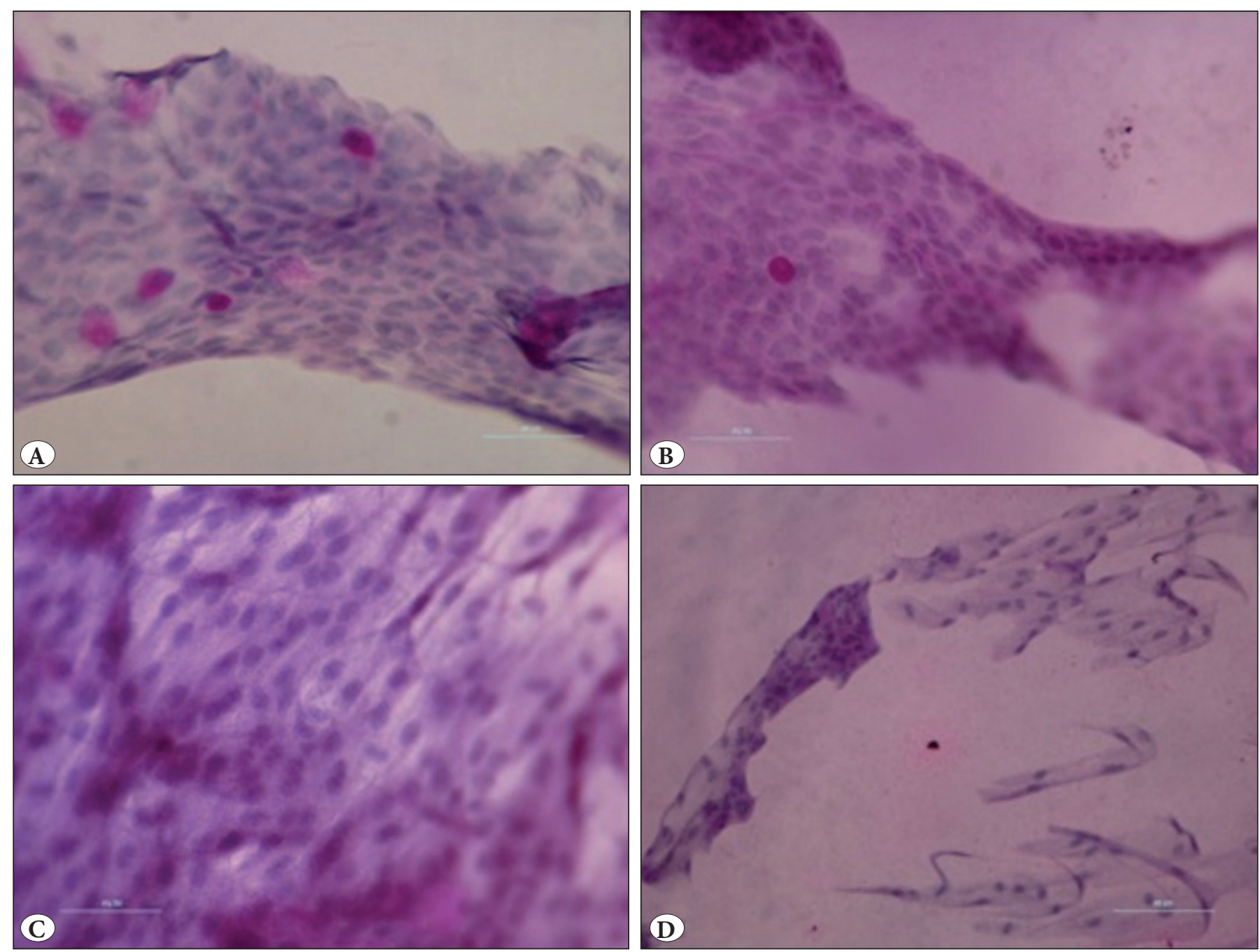

Figure 1: Grading system of impression cytology. A) Grade 0: small, ground epithelial cells have a prominent nucleus (PAS stain; $\mathrm{x} 400$ ). B) Grade 1: the epithelial cells are slightly larger. The nuclei are smaller. Goblet cells are decreased minimally (PAS stain; x200). C) Grade 2: larger and polygonal epithelial cells (N/C ratio 1:4-1:5). Goblet cells are smaller and markedly decreased (PAS stain; x200). D) Grade 3: goblet cells have disappeared (N/C ratio 1:6) (PAS stain; $\mathrm{x} 400$ ). 


\section{RESULTS}

A total of 61 volunteer participants, including 9 men (14.8\%) and 52 women (85.2\%) were involved in this study. The participants were divided into two groups for analysis: an obesity group ( $n=20,32.8 \%)$ and a control group $(n=41$, $67.2 \%)$. There was no significant difference between the two groups in terms of age or sex. Table I shows the demographic and clinical characteristics of both the obesity and control groups.

There was a certain level loss of goblet cells in $90 \%$ and squamous metaplasia (Nelson grade $2-3$ ) in $80 \%$ of obese participants and the impression cytology was found to be normal in only two patients (10\%). The rate of participants without abnormal cytology was $56.1 \%$ in the control group, and the squamous metaplasia rate was nearly $17 \%(\mathrm{p}<0.001)$. Furthermore, the average BMI, insulin, glucose and HOMA IR levels were significantly higher in the obesity group $(\mathrm{p}<0.001)$. When the participants were grouped according to grade level, a gradual increase in the average BMI, insulin, glucose, and HOMA IR levels was observed in association with the increase in grade levels (Table II). 90.9\% ( $n=10)$ of those with grade 3 were obese. Grade 1 was found in only one of the patients belonging to the control group. Table II indicates both the demographic and clinical data associated with these grade levels.

Importantly, there was a certain level of goblet cell loss found in $59 \%(\mathrm{n}=36)$ of all of population involved in this study. Of these, $36.1 \%(\mathrm{n}=13)$ had grade $1,33.3 \%(\mathrm{n}=12)$ had grade 2 , and $30.6 \%(n=11)$ had grade 3 cytology. For those with abnormal cytology, the average BMI was $32.1 \pm 8.3$, insulin was $23.2 \pm 7.7$, glucose was $100.8 \pm 14.7$, and HOMA IR was $5.9 \pm 1.7$. These values were significantly higher $(\mathrm{p}<0.001)$ compared to those with the normal impression cytology. Table III indicates both the demographic and clinical data associated with abnormal cytology.

Table I: The distribution of clinical and demographic results by obesity presence.

\begin{tabular}{|c|c|c|c|}
\hline \multirow[b]{2}{*}{ The variables } & \multicolumn{2}{|c|}{ Obesity } & \multirow[b]{2}{*}{$\mathbf{p}$} \\
\hline & $\begin{array}{c}\text { No } \\
n=41\end{array}$ & $\begin{array}{c}\text { Yes } \\
n=20\end{array}$ & \\
\hline \multicolumn{4}{|l|}{ Sex } \\
\hline Female & $34(82.9)$ & $18(90.0)$ & \multirow{2}{*}{0.704} \\
\hline Male & $7(17.1)$ & $2(10.0)$ & \\
\hline Age & $33.5 \pm 5.9$ & $36.7 \pm 10.2$ & 0.130 \\
\hline $\mathrm{BMI}$ & $24.7 \pm 2.8$ & $38.2 \pm 5.8$ & $<0.001$ \\
\hline \multicolumn{4}{|l|}{ Grade } \\
\hline 0 & $23(56.1)$ & $2(10.0)$ & \multirow{4}{*}{$<0.001$} \\
\hline 1 & $11(26.8)$ & $2(10.0)$ & \\
\hline 2 & $6(14.6)$ & $6(30.0)$ & \\
\hline 3 & $1(2.4)$ & $10(50.0)$ & \\
\hline \multicolumn{4}{|l|}{ Abnormal Cytology } \\
\hline No & $23(56.1)$ & $2(10.0)$ & \multirow{2}{*}{0.001} \\
\hline Yes & $18(43.9)$ & $18(90.0)$ & \\
\hline Insulin & $13.9 \pm 3.4$ & $26.6 \pm 7.3$ & $<0.001$ \\
\hline Glucose & $87.8 \pm 8.2$ & $108.2 \pm 14.1$ & $<0.001$ \\
\hline HOMA IR & $3.0 \pm 1.3$ & $7.2 \pm 2.3$ & $<0.001$ \\
\hline
\end{tabular}

BMI: Body Mass Index, HOMA IR: Homeostasis model assessment for insulin resistance, Grade: Impression cytology Nelson grade.

Table II: The distribution of clinical and demographic results by grade level.

\begin{tabular}{|c|c|c|c|c|c|}
\hline \multirow[b]{2}{*}{ The variables } & \multicolumn{4}{|c|}{ Grade } & \multirow[b]{2}{*}{$\mathbf{p}$} \\
\hline & $\begin{array}{c}0 \\
n=25\end{array}$ & $\begin{array}{c}1 \\
n=13\end{array}$ & $\begin{array}{c}2 \\
n=12\end{array}$ & $\begin{array}{c}3 \\
n=11\end{array}$ & \\
\hline \multicolumn{6}{|l|}{ Sex } \\
\hline Female & $20(80.0)$ & $11(84.6)$ & $10(83.3)$ & $11(100.0)$ & \multirow{2}{*}{0.502} \\
\hline Male & $5(20.0)$ & $2(15.4)$ & $2(16.7)$ & - & \\
\hline Age & $34.2 \pm 5.8$ & $35.3 \pm 8.2$ & $34.5 \pm 11.4$ & $34.3 \pm 6.6$ & 0.981 \\
\hline BMI & $24.9 \pm 3.0$ & $27.7 \pm 9.1$ & $32.0 \pm 6.5$ & $37.5 \pm 6.0$ & $<0.001$ \\
\hline \multicolumn{6}{|l|}{ Obesity } \\
\hline No & $23(92.0)$ & $11(84.6)$ & $6(50.0)$ & $1(9.1)$ & \multirow{2}{*}{$<0.001$} \\
\hline Yes & $2(8.0)$ & $2(15.4)$ & $6(50.0)$ & $10(90.9)$ & \\
\hline Insulin & $10.6 \pm 3.1$ & $17.7 \pm 3.0$ & $21.6 \pm 3.3$ & $31.4 \pm 7.4$ & $<0.001$ \\
\hline Glucose & $85.5 \pm 6.5$ & $90.6 \pm 11.6$ & $102.8 \pm 15.9$ & $110.6 \pm 8.4$ & $<0.001$ \\
\hline HOMA IR & $2.2 \pm 7.2$ & $3.9 \pm 0.5$ & $5.5 \pm 1.4$ & $8.7 \pm 2.6$ & $<0.001$ \\
\hline
\end{tabular}

BMI: Body Mass Index, HOMA IR: Homeostasis model assessment for insulin resistance, Grade: Impression cytology Nelson grade. 
There was a positive correlation between BMI and the age, alongside insulin, glucose, and HOMA IR levels within the given population. The positive correlation between the BMI level and insulin level, glucose level and HOMA IR levels remained stable in those patients with abnormal cytology; however, a significant relationship with age was lost. A correlation between the BMI versus the insulin, glucose, and HOMA IR levels was not observed in patients without abnormal cytology or obesity (Table IV).

The likely risk factors associated with abnormal cytology were plugged into the multiple regression model. The BMI (OR=1.24; $\mathrm{p}=0.002)$ and HOMA IR $(\mathrm{OR}=28.6$; $\mathrm{p}=0.001$ ) were estimated as being independent predictors that indicated the presence of abnormal cytology in Model I, as observed with the multivariable regression model encompassing BMI, insulin, glucose, and HOMA IR variables. Hence, while an increase of one $\mathrm{kg} / \mathrm{m}^{2}$ in BMI level causes the risk of goblet cell loss to increase in the conjunctiva by a factor of 1.24 , a similar one unit of increase in HOMA IR level causes the risk of goblet cell loss to increase by a factor of 28.6.

Table III: The distribution of clinical and demographic results by abnormal cytology presence.

\begin{tabular}{|c|c|c|c|}
\hline \multirow[b]{2}{*}{ The variables } & \multicolumn{2}{|c|}{ Abnormal cytology } & \multirow[b]{2}{*}{$\mathbf{p}$} \\
\hline & $\begin{array}{c}\text { No } \\
n=25\end{array}$ & $\begin{array}{c}\text { Yes } \\
\mathrm{n}=36\end{array}$ & \\
\hline \multicolumn{4}{|l|}{ Sex } \\
\hline Female & $20(80.0)$ & $32(88.9)$ & \multirow{2}{*}{0.467} \\
\hline Male & $5(20.0)$ & $4(11.1)$ & \\
\hline Age & $34.2 \pm 5.8$ & $34.7 \pm 8.8$ & 0.811 \\
\hline BMI & $24.9 \pm 3.0$ & $32.1 \pm 8.3$ & $<0.001$ \\
\hline \multicolumn{4}{|l|}{ Obesity } \\
\hline No & $23(92.0)$ & $18(50.0)$ & \multirow{2}{*}{0.001} \\
\hline Yes & $2(8.0)$ & $18(50.0)$ & \\
\hline \multicolumn{4}{|l|}{ Grade } \\
\hline 0 & $25(100.0)$ & - & \multirow{4}{*}{$<0.001$} \\
\hline 1 & - & $13(36.1)$ & \\
\hline 2 & - & $12(33.3)$ & \\
\hline 3 & - & $11(30.6)$ & \\
\hline Insulin & $10.6 \pm 3.1$ & $23.2 \pm 7.7$ & $<0.001$ \\
\hline Glucose & $85.5 \pm 6.6$ & $100.8 \pm 14.7$ & $<0.001$ \\
\hline HOMA IR & $2.2 \pm 0.7$ & $5.9 \pm 1.7$ & $<0.001$ \\
\hline
\end{tabular}

BMI: Body Mass Index, HOMA IR: Homeostasis model assessment for insulin resistance, Grade: Impression cytology Nelson grade.
The BMI $(\mathrm{OR}=11.91 ; \mathrm{p}=0.002)$ and HOMA IR $(\mathrm{OR}=15.08$; $\mathrm{p}<0.001)$ were estimated as being independent predictors that indicated the presence of obesity in the Model II developed with the multivariable regression model employing BMI, insulin, glucose, and HOMA IR variables. Therefore, the goblet cell loss risk was 11.91 times higher in obese patients compared to non-obese patients. It was found that a one unit of increase in HOMA IR level had caused the goblet cell loss risk to increase by a factor of 15.08 (Table V). Additionally, the diagnostic potential of the BMI, insulin, glucose, and HOMA IR levels in predicting the goblet cell loss risk was evaluated using ROC Curve analysis. Thus, the HOMA IR level had a higher diagnostic ability compared to BMI and obesity. BMI and obesity also had similar diagnostic capability (Figure 2).

Table IV: The distribution of clinical and demographic results by BMI level.

\begin{tabular}{|c|c|c|c|}
\hline \multirow{2}{*}{\multicolumn{2}{|c|}{ The variables }} & \multicolumn{2}{|c|}{ BMI } \\
\hline & & \multirow{2}{*}{$\begin{array}{c}\mathbf{r} \\
0.274 \\
\end{array}$} & \multirow{2}{*}{$\begin{array}{c}p \\
0.032 \\
\end{array}$} \\
\hline \multirow{4}{*}{ 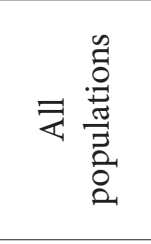 } & Age & & \\
\hline & Insulin & 0.586 & $<0.001$ \\
\hline & Glucose & 0.658 & $<0.001$ \\
\hline & HOMA IR & 0.647 & $<0.001$ \\
\hline \multirow{4}{*}{ 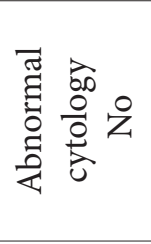 } & Age & 0.225 & 0.279 \\
\hline & Insulin & 0.086 & 0.683 \\
\hline & Glucose & -0.192 & 0.156 \\
\hline & HOMA IR & 0.007 & 0.973 \\
\hline \multirow{4}{*}{ 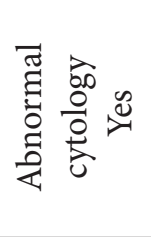 } & Age & 0.214 & 0.062 \\
\hline & Insulin & 0.468 & $<0.001$ \\
\hline & Glucose & 0.660 & $<0.001$ \\
\hline & HOMA IR & 0.570 & $<0.001$ \\
\hline \multirow{4}{*}{ 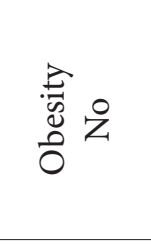 } & Age & 0.162 & 0.311 \\
\hline & Insulin & 0.057 & 0.723 \\
\hline & Glucose & 0.085 & 0.598 \\
\hline & HOMA IR & 0.076 & 0.635 \\
\hline \multirow{4}{*}{ 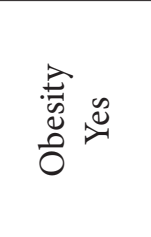 } & Age & 0.236 & 0.317 \\
\hline & Insulin & 0.324 & 0.032 \\
\hline & Glucose & 0.495 & $<0.001$ \\
\hline & HOMA IR & 0.360 & 0.010 \\
\hline
\end{tabular}

BMI: Body Mass Index, HOMA IR: Homeostasis model assessment for insulin resistance. 
Table V: The independent predictors/variables indicating the existence of abnormal cytology.

\begin{tabular}{|c|c|c|c|c|}
\hline \multirow{2}{*}{ The variables } & \multirow{2}{*}{ OR } & \multicolumn{2}{|c|}{$95 \% \mathrm{CI}$} & \multirow[b]{2}{*}{$\mathbf{p}$} \\
\hline & & lower & upper & \\
\hline \multicolumn{5}{|l|}{ Model I } \\
\hline BMI & 1.24 & 1.09 & 1.423 & $0.002^{*}$ \\
\hline \multirow[t]{2}{*}{ HOMA IR } & 28.6 & 2.95 & 277.41 & $0.001^{\star}$ \\
\hline & \multicolumn{4}{|c|}{ Nagelkerker $\mathrm{R}=0.531 ; \mathrm{p}<0.001^{*}$} \\
\hline \multicolumn{5}{|l|}{ Model II } \\
\hline Obesity & 11.91 & 2.39 & 59.29 & $0.002^{\star}$ \\
\hline HOMA IR & 15.08 & 3.29 & 69.16 & $<0.001^{\star}$ \\
\hline & \multicolumn{4}{|c|}{ Nagelkerker $\mathrm{R}=0.610 ; \mathrm{p}<0.001^{\star}$} \\
\hline
\end{tabular}

Model I: The BMI, insulin level, glucose level and HOMA IR variables were included in the multivariable regression models.

Model II: The BMI, obesity, insulin level, glucose level and HOMA IR variables were included in the multivariable regression models.

\section{DISCUSSION}

In our study, we have observed that obesity causes abnormal cytology and squamous metaplasia in conjunctival surface epithelial cells. We thought that this may be due to systemic inflammation. The presence of obesity, BMI, and HOMA IR levels were found to be independent risk factors, thus advancing the impression cytology grade in conjunctiva.

While obesity is known to be a systemic disease that affects many organs, its effects on the eyes has not yet been clearly identified. However, a handful of recent studies indicate that there is a relationship between obesity and certain types of eye diseases such as cataract, glaucoma, retinopathy, maculopathy, and dry eye disease (12-14). A handful of different theories have been put forth that explain the mechanisms behind such complications. For example, hormonal changessuch as an increaseinleptin and a decrease in ghrelin, vascular changes (a decrease in vasodilator levels such as nitric oxide, a increase in vasoconstrictor levels such as Endothelin 1 and Angiotensin 2), mechanic factors (i.e. an increase in intraorbital fat tissue), and oxidative stress are likely factors that may cause the development of ocular complications in obese patients (12,15-17). Furthermore, Baser et al., have indicated that there is a relationship between the increase of BMI and Meibomian gland dysfunction, thus causing the development of dry eye disease (9). Another essential mechanism is the activation of systematic chronic inflammation and immune system (4-7). For the first time, Hotamisligil et al., has shown an increase of TNF-alpha expression in the fat tissue of obese patients, which has a direct influence on insulin resistance (18). A number of other studies indicated that increased adipose tissue was shown to cause up-regulation

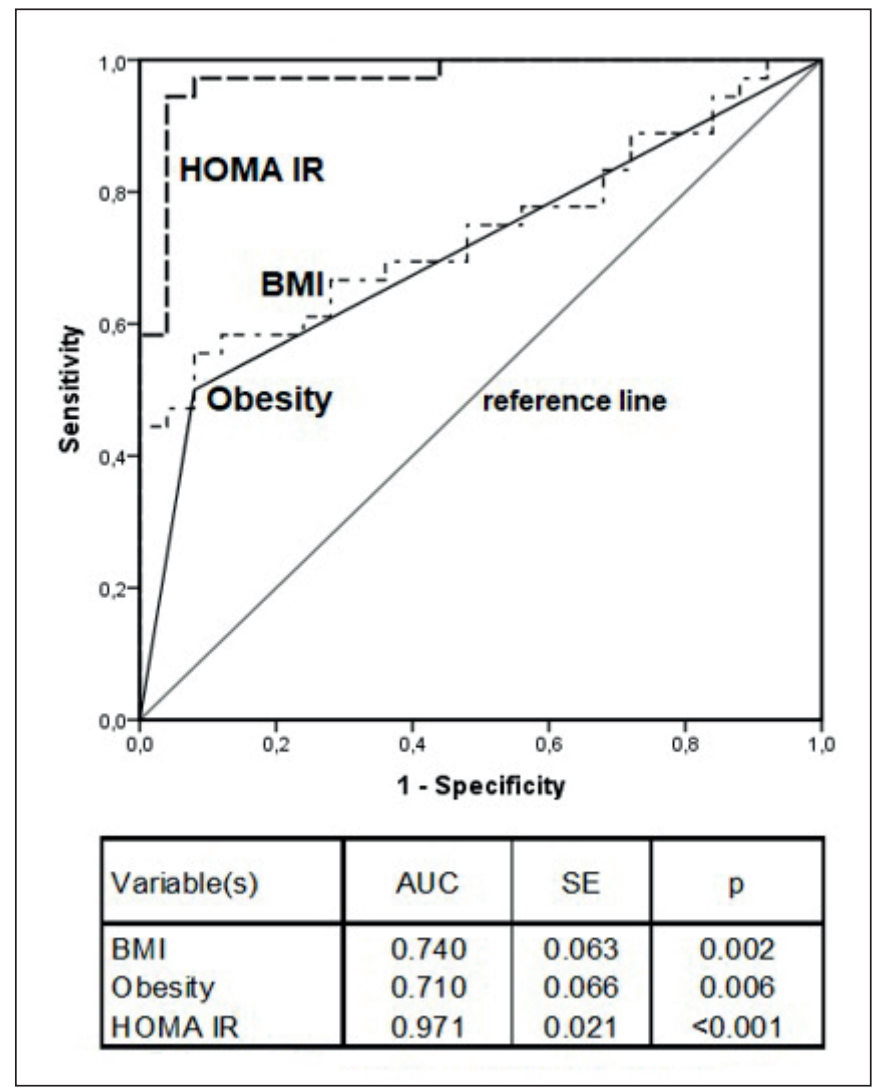

Figure 2: The diagnostic ability of the BMI and the insulin and HOMA IR levels to predict abnormal cytology.

BMI: Body Mass Index, HOMA IR: Homeostasis model assessment for insulin resistance, AUC: Area Under the Curve, SE: Standard error.

in genes encoding inflammatory factors, activation in c-Jun $\mathrm{N}$-terminal kinase (JNK) and nuclear factor-kappa B (NF$\mathrm{\kappa B})$ pathways, and also increase in production of some cytokines and chemokines (4-7). Although the main source of inflammation is adipose tissue, it was shown that the liver, pancreas, brain, and muscle tissue also contribute to the inflammatory response (19). The primary markers influencing the inflammation include coagulative factors such as white blood cells, fibrinogen, and plasminogen activator inhibitors (PAI-1); acute phase proteins such as serum Amyloids A (SAA); and pro-inflammatory cytokines and chemokines such as TNF-alpha, IL-1 $\beta$ and IL-6 (20-25). The inflammatory response moderately and frequently endures as long as it is not induced with a stimulant such as trauma or acute immune response (19). The two pathologic processes causing loss of goblet cells in squamous metaplasia include the loss of vascularization and intense inflammation (26). A number of matrix protease inhibitors resemble anti-inflammatory factors such as the $\mathrm{T}$ lymphocytes, IL- 1 receptor antagonists, TGF- $\beta 2$, and tissue inhibitors of metalloproteinase-1 (TIMP-1) 
and all play important roles in the immune balance of the ocular surface (27). When all of the aforementioned mechanisms are considered together, it can be thought that the inflammatory response developing in obesity may destroy the immune system balance and thus cause the development of inflammation on conjunctival epithelium cells. This may be attributed to the results of earlier research regarding obesity causing inflammation on the ocular surface cells of patients with certain autoimmune and inflammatory diseases such as autoimmune thyroid disease, diabetes mellitus, inflammatory colon disease, and chronic kidney disease (28-31). The development of dry eye disease was found to be responsible for the inflammation caused by some of these diseases. In our study, however, dry eye disease was either excluded or disqualified as based on Schirmer's test. Although the primary reason for the development of squamous metaplasia is thought to be systemic inflammation, the hormonal and vascular changes may have either caused or contributed to the development of this situation.

Obesity is the main reason behind the lessening in insulin vulnerability, thus resulting in insulin resistance (IR) occurring in most of the patients (32-34). It is thought that insulin resistance plays an important role in inflammation $(35,36)$. The existence of the relationship between IR and the immune system was demonstrated for the first time through studies showing the increase of insulin resistance based on infections $(37,38)$. These studies have also shown that there is a positive correlation between insulin resistance and pro-inflammatory cytokine levels $(20,21,39)$. We have found a strong relationship between the worsening of the grade in conjunctiva and IR (insulin level and HOMA IR index). In other words, the existence as well as strength of insulin resistance appears to be an independent risk factor for squamous metaplasia.

Glucose metabolism disorders are also frequently associated with obesity (40). DM is a disease that develops due to systemic inflammation (40). Little in the way of research exists that shows the increase of the frequency of conjunctival squamous metaplasia in diabetes, and what exists only shows that this is related to the poor control of diabetes (41-43). There was no diabetes in our study; however, we did determine that there is a relationship between glucose levels and the development of squamous metaplasia.

The formation or origination mechanism of the conjunctival squamous metaplasia developed in most systemic diseases such as obesity, DM and IR has not yet been clearly understood. However, numerous studies have claimed that the most important mechanism is dry eye disease, which is caused by the effect of the tear gland. In addition, there are also other important studies showing that other factors such as inflammation (which directly affect the epithelium cells) may play an important role in the development of the disease (43). Our study is crucial in that not only does it indicate directly the relationship between obesity and conjunctival squamous metaplasia for the first time, but it also supports the idea that other factors such as primary systemic inflammation alongside dry eye disease may also play an important role in its development mechanism.

There are, however, some limitations to our study. The number of patients participating in the study was insufficient. Furthermore, we did not examine data such as systemic inflammation markers or leptin and ghrelin levels, which are more objectively able to indicate the relationships of squamous metaplasia with systemic inflammation and other mechanisms.

In conclusion, our study is the first to indicate that the ocular surface cells can be affected by obesity. Such situations may lead to certain vision problems in conjunction with other obesity-related ocular complications. Routine eye examinations therefore need to be conducted, whereby ocular surface cells are evaluated carefully during the follow up of obese patients, this in turn requiring a multidisciplinary approach. More comprehensive future research into this subject seems to be necessary.

\section{CONFLICT of INTEREST}

The authors report no conflicts of interest. The authors alone are responsible for the content and writing of the paper.

\section{REFERENCES}

1. Flegal KM, Carroll MD, Kit BK, Ogden CL. Prevalence of obesity and trends in the distribution of body mass index among US adults, 1999-2010. JAMA. 2012;307:491- 7.

2. Finucane MM, Stevens GA, Cowan MJ, Danaei G, Lin JK, Paciorek JC, Singh GM, Gutierrez HR, Lu Y, Bahalim AN, Farzadfar F, Riley LM, Ezzati M. National, regional, and global trends in body-mass index since 1980: Systematic analysis of health examination surveys and epidemiological studies with 960 country-years and 9.1 million participants. Lancet. 2011;377:55767.

3. Hotamisligil GS. Inflammation and metabolic disorders. Nature 2006;444:860-7.

4. Shoelson SE, Lee J, Goldfine AB. Inflammation and insulin resistance. J Clin Invest. 2006;116:1793-801.

5. Donath MY, Shoelson SE. Type 2 diabetes as an inflammatory disease. Nat Rev Immunol. 2011;11:98-107. 
6. Chawla A, Nguyen KD, Goh YP. Macrophage-mediated inflammation in metabolic disease. Nat Rev Immunol. 2011;11:738-49.

7. Ouchi N, Parker JL, Lugus JJ, Walsh K. Adipokines in inflammation and metabolic disease. Nat Rev Immunol. 2011;11:85-97.

8. Chang RC, Shi L, Huang CC, Kim AJ, Ko ML, Zhou B, Ko GY. High-fat diet-induced retinal dysfunction. Invest Ophthalmol Vis Sci. 2015;56: 2367-80.

9. Baser G, Yıldiz N, Calan M. Evaluation of meibomian gland dysfunction in polycystic ovary syndrome and obesity. Curr Eye Res. 2017;42: 661-5.

10. Kim HT, Kim JM, Kim JH, Lee JH, Lee MY, Lee JY, Won YS, Park KH, Kwon HS. Relationships between anthropometric measurements and intraocular pressure: The Korea National Health and Nutrition Examination Survey. Am J Ophthalmol. 2017;173: 23-33.

11. Tiruvalluru M, Ananthathmakula P, Ayyalasomayajula V, Nappanveettil G, Ayyagari R, Reddy GB. Vitamin A supplementation ameliorates obesity-associated retinal degeneration in WNIN/Ob rats. Nutrition. 2013;29: 298-304.

12. Dogan B, Kazim EM, Dogan U, Habibi M, Bulbuller N, Turgut Coban D, Bulut M. The retinal nerve fiber layer, choroidal thickness, and central macular thickness in morbid obesity: An evaluation using spectral-domain optical coherence tomography. Eur Rev Med Pharmacol Sci. 2016;20: 886-91.

13. Singh R, Joseph A, Umapathy T, Tint NL, Dua HS. Impression cytology of the ocular surface. Br J Ophthalmol. 2005;89:1655-9.

14. Cheung N, Wong TY. Obesity and eye disease. Surv Ophthalmol. 2007;52:180-95.

15. Butt Z, O’brien C, Mckillop G, Aspinall P, Allan P. Color Doppler imaging in untreated high-and normal -pressure open-angle glaucoma. Invest Ophthalmol Vis Sci. 1997;38:690-6.

16. Gherghel D, Orgul S, Gugleta K, Gekkieva M, Flammer J. Relationship between ocular perfusion pressure and retrobulbar blood flow in patients with glaucoma with progressive damage. Am J Ophthalmol. 2000;130:597-605.

17. Ferreira SM, Lerner SF, Brunzini R, Evelson PA, Llesuy SF. Oxidative stres markers in aqueous humor of glaucoma patients. Am J Ophthalmol. 2004;137:62-9.

18. Hotamisligil GS, Arner P, Caro JF, Atkinson RL, Spiegelman BM. Increased adipose tissue expression of tumor necrosis factoralpha in human obesity and insulin resistance. J Clin Invest. 1995;95:2409-15.

19. Gregor MF, Hotamisligil GS. Inflammatory mechanisms in obesity. Annu Rev Immunol. 2011;29: 415-45.

20. Pickup JC, Mattock MB, Chusney GD, Burt D. NIDDM as a disease of the innate immune system: Association of acutephase reactants and interleukin-6 with metabolic syndrome X. Diabetologia. 1997;40:1286-92.

21. Yudkin JS, Stehouwer CD, Emeis JJ, Coppack SW. C-reactive protein in healthy subjects: Associations with obesity, insulin resistance, and endothelial dysfunction: A potential role for cytokines originating from adipose tissue? Arterioscler Thromb Vasc Biol. 1999;19:972-8.
22. Bastard JP, Jardel C, Bruckert E, Blondy P, Capeau J, Laville M, Vidal H, Hainque B. Elevated levels of interleukin 6 are reduced in serum and subcutaneous adipose tissue of obese women after weight loss. J Clin Endocrinol Metab. 2000;85:3338-42.

23. Haffner S, Temprosa M, Crandall J, Fowler S, Goldberg R, Horton E, Marcovina S, Mather K, Orchard T, Ratner R, Barrett-Connor E. Intensive lifestyle intervention or metformin on inflammation and coagulation in participants with impaired glucose tolerance. Diabetes. 2005;54:1566-72.

24. Bruun JM, Helge JW, Richelsen B, Stallknecht B. Diet and exercise reduce low-grade inflammation and macrophage infiltration in adipose tissue but not in skeletal muscle in severely obese subjects. Am J Physiol Endocrinol Metab. 2006;290:961-7.

25. Belalcazar LM, Haffner SM, Lang W, Hoogeveen RC, Rushing J, Schwenke DC, Tracy RP, Pi-Sunyer FX, Kriska AM, Ballantyne CM. Lifestyle intervention and/or statins for the reduction of C-reactive protein in type 2 diabetes: From the look AHEAD study. Obesity. 2013;21:944-50.

26. Tseng SC, Hirst LW, Maumenee AE, Kenyon KR, Sun TT, Green WR. Possible mechanisms for the loss of goblet cells in mucindeficient disorders. Ophthalmology. 1984;91:545-52.

27. Baudouin C, Irkeç M, Messmer EM, Benítez del Castillo JM, Bonini S, Figueiredo FC, Geerling G, Labetoulle M, Lemp M, Rolando M, Van Setten G, Aragona P. Clinical impact of inflammation in dry eye disease: Proceedings of the ODISSEY group meeting. Acta Ophthalmol. 2018;96:111-9.

28. Kesarwani D, Rizvi SWA, Khan AA, Amitava AK, Vasenwala SM, Siddiqui Z. Tear film and ocular surface dysfunction in diabetes mellitus in an Indian population. Indian J Ophthalmol. 2017;65: 301-4.

29. Demir N, Altay M, Özer E, Ünlü N, Duranay M, Üstün H, Duman S. Duration of renal failure as risk factor for conjunctival squamous metaplasia. Acta Cytol. 2008; 52:309-12.

30. Uzel MM, Citirik M, Kekilli M, Cicek P. Local ocular surface parameters in patients with systemic celiac disease. Eye. 2017;31:1093-8.

31. Kocabeyoglu S, Mocan MC, Cevik Y, Irkec M. Ocular surface alterations and in vivo confocal microscopic features of corneas in patients with newly diagnosed graves' disease. Cornea. 2015;34:745-9.

32. Mohanraj L, Kim HS, Li W, Cai Q, Kim KE, Shin HJ, Lee YJ, Lee WJ, Kim JH, Oh Y. IGFBP-3 inhibits cytokine-induced insulin resistance and early manifestations of atherosclerosis. PLoS ONE. 2013;8(1): e55084.

33. Daniele G, Mendoza RG, Winnier D, Fiorentino TV, Pengou Z, Cornell J, Andreozzi F, Jenkinson C, Cersosimo E, Federici $\mathrm{M}$, Tripathy D, Folli F. The inflammatory status score including IL-6, TNF- $\alpha$, osteopontin, fractalkine, MCP-1 and adiponectin underlies whole-body insulin resistance and hyperglycemia in type 2 diabetes mellitus. Acta Diabetol. 2014;51:123-31.

34. Osborn O, Olefsky JM. The cellular and signaling networks linking the immune system and metabolism in disease. Nat Med. 2012;18:363-74.

35. Chen L, Chen R, Wang H, Liang F. Mechanisms linking inflammation to insulin resistance. Int $\mathrm{J}$ Endocrinol. 2015;2015:508409. 
36. Esser N, Legrand-Poels S, Piette J, Scheen AJ, Paquot N. Inflammation as a link between obesity, metabolic syndrome and type 2 diabetes. Diabetes Res Clin Pract. 2014:105: 141-50.

37. Clowes GH Jr, Martin H, Walji S, Hirsch E, Gazitua R, Goodfellow R. Blood insulin responses to blood glucose levels in high output sepsis and septic shock. Am J Surg. 1978:135:577-83.

38. Wichterman KA, Chaudry IH, Baue AE. Studies of peripheral glucose uptake during sepsis. Arch Surg. 1979;114:740-5.

39. Phillips CM, Perry IJ. Does inflammation determine metabolic health status in obese and nonobese adults? J Clin Endocrinol Metab. 2013;98:1610-9.

40. Alberti KG, Eckel RH, Grundy SM, Zimmet PZ, Cleeman JI, Donato KA, Fruchart JC, James WP, Loria CM, Smith SC Jr. Harmonizing the metabolic syndrome: A joint interim statement of the International Diabetes Federation Task Force on Epidemiology and Prevention; National Heart, Lung, and Blood Institute; American Heart Association; World Heart Federation; International Atherosclerosis Society; and International Association for the Study of Obesity. Circulation. 2009;120: 1640-5.
41. Yoon KC, Im SK, Seo MS. Changes of tear film and ocular surface in diabetes mellitus. Korean J Ophthalmol. 2004:18:168-74.

42. Li HY, Pang GX, Xu ZZ. Tear film function of patients with type 2 diabetes. Zhongguo Yi Xue Ke Xue Yuan Xue Bao. (Acta Academiae Medicinae Sinicae) 2004;26:682-6.

43. Alves Mde C, Carvalheira JB, Módulo CM, Rocha EM. Tear film and ocular surface changes in diabetes mellitus. Arq Bras Oftalmol. 2008;71:96-103. 